\title{
PUBLIC KNOWLEDGE AND ATTITUDE TOWARD DEPRESSION AND SCHIZOPHRENIA: FINDINGS FROM QUANTITATIVE STUDY IN UAE
}

\author{
SUNDOS QASSIM ${ }^{1}$, FATIMA BOURA ${ }^{1}$, YASSIN AL-HARIRI ${ }^{2 *}$ \\ ${ }^{1}$ Department of Pharmaceutical Sciences, College of Pharmacy and Health Sciences, Ajman University, Ajman, UAE. ${ }^{2}$ Department of Clinical \\ Sciences, College of Pharmacy and Health Sciences, Ajman University, Ajman, UAE. Email: y.alhariri@ajman.ac.ae
}

Received: 22 March 2018, Revised and Accepted: 18 April 2018

\section{ABSTRACT}

Objective: The purpose of the current study to assess current attitude and knowledge of UAE population toward mental disorders, and to determine the stigma status of people with schizophrenia and depression.

Methods: A represented sample of 430 participants was enrolled in the study. A descriptive qualitative survey was the study tool. The developed questionnaire was designed to be interview-administrated SPSS 24 used in data analysis. A correlation analysis was performed to test association. Oneway ANOVA and independent t-test were applied to determine which factors might affect the knowledge and attitude score. p $<0.05$ was considered significant.

Results: The study findings revealed a high level of stigma among UAE population toward people with schizophrenia and depression. 62\% (266) had negative attitude score while $38.1 \%$ (164) had positive attitude score. $67 \%$ of the participants believe that people with schizophrenia and depression are dangerous. $80 \%$ (343) had a good knowledge score while 20.2\% (87) had poor knowledge score.

Conclusion: The negative attitude confirms the importance of increasing mental health literacy. These findings highlight the need to implement national mental health policy to educate the public and reduce the stigma of mental disorders.

Keywords: Stigma, Mental health literacy, Schizophrenia, Depression, Attitude, Knowledge.

(c) 2018 The Authors. Published by Innovare Academic Sciences Pvt Ltd. This is an open access article under the CC BY license (http://creativecommons. org/licenses/by/4. 0/) DOI: http://dx.doi.org/10.22159/ajpcr.2018.v11i7.26061

\section{INTRODUCTION}

Mental health has been widely recognized as challenging public health issue [1-4]. Mental illness is a serious burden for developed and non-developed countries [5,6]. Mental health problems are leading causes of the non-communicable burden, because of being accounted for $6.6 \%$ of global disability-adjusted life years and $18.9 \%$ of global years lived with disability [2].

Mental health literacy (MHL) has been defined as "knowledge and beliefs about mental disorders which aid their recognition, management, or prevention" [2,6,7]. The definition of MHL includes awareness and perception about mental illnesses, which support their recognition; the ability to identify specific disorders; knowing how to seek professional help; knowledge of risk factors and causes, and attitudes that promote identification [2,7-11]. Numerous countries include improving health literacy as one of the future health national agenda [8].

In the west, depression and schizophrenia are the frequently observed mental illnesses [1]. There is some evidence suggests life events, particularly stress social environment, may trigger the cause of schizophrenia and depression $[1,5,12]$.

Stigma defined as "the convergence of the following four interrelated components: (i) People identify and label human differences; (ii) people associate the differences with undesirable characteristics; (iii) people accomplish some degree of separation of "us" from "them;" and (iv) labeled persons experience status loss and discrimination" [13,14]. Individual discrimination defined as "the behavior of individual members of one group that is intended to have a differential and/or harmful effect on the members of another group" [13,14].

Mental health disorder is one of the most stigmatized diseases world wild [15-17]. Stigma has a negative impact on different life domain though both experienced and anticipated discrimination [15-17]. Unfortunately, literature revealed that people with mental illness are being treated as second-class citizen $[15,17]$. Moreover, in term of employment, they are the first to fire and the last to hire, while in term of community housing they are being unwelcome neighbors [15-17]. Because of stigma, people with mental illness suffer from rejection, discrimination, and distress [18]. Further, stigma experience correlates with reduced self-esteem and satisfaction [18].

There are considerable studies documenting low knowledge and negative attitudes toward mentally ill patients $[1,10,11,19]$. Crosscultural research has shown that non-Western countries tend to view mental illnesses more negatively than Western countries [5]. Various studies reported a false recognizing of the term schizophrenia as split personality $[1,5]$.

Public attitude regarding mental health problems will have a major impact on the social acceptance and integration [20]. Community's beliefs, attitudes, and knowledge regarding mental illness will affect the disease detection and health outcome. An essential objective of mental health research is to prompt solution to reduce stigma [21]. Thus, the aim of the current study was to determine current attitudes and knowledge toward schizophrenia and depression, evaluate the extent to which demographic factors are associated with knowledge and attitude, and to determine the stigma pattern among UAE population to schizophrenia and depression.

\section{METHODS}

A descriptive qualitative survey was carried out over the UAE for exploring and collecting data from UAE population. Convenience sampling was used as a sampling method. Raosoft online sample calculator was used in calculating the minimum sample size required 
(430) [22]. A structured questionnaire was designed by the researcher based on parameters to be evaluated as part of the study and by referring to previous literature [1].

The questionnaire was modified to make it convenient for UAE population. The questionnaire composed of three different sections. Section one contains questions related to the population's demographic characteristics. Section two explores the respondents' knowledge regarding the cause of depression and schizophrenia. Section three was composed of seven statements to determine the participant's attitude.

The survey tool was reviewed by university lecturers and academics with a wide range of professional experience to establish content validity of the questionnaire. Participants were informed that participation is voluntary. Feedback given by the pilot study population was considered, and corrections were made accordingly. Questions adjustments were made to the questionnaire to improve its validity. Participants who were willing to be enrolled in this study were asked to sign informed consent forms. Health care providers and people not willing to participate in the study were excluded from the study. The developed questionnaire was designed to be interview-administrated. The interviewer intervened only to clarify a question if required. No attempt was made to prompt the respondents by suggesting answers directly.

Data analysis was conducted using SPSS version 24. Instituting identification numbers were given for all questionnaires. All questions were coded, and then they were imported to SPSS for analysis. The objectives were also analyzed by descriptive analysis. The descriptive statistics included mean, median, standard deviation, and frequency. For the attitude items, the coding was established by giving 1 mark for the positive attitude answers, and zero for both the negative attitude answers and do not know choice. Positive perception level considered for score value above the mean/median score and negative perception level considered for score value below the mean/median score.

Results were presented as numbers with percentages or graphic presentations for categorical variables. A correlation analysis was performed to test association. One-way ANOVA and independent t-test were applied to determine which factors might affect the knowledge and attitude score. $\mathrm{p}<0.05$ was considered significant.

\section{RESULTS}

Sociodemographic data of the respondents

The sociodemographic characteristic of the study participants is listed in Table 1. A total number of 430 people from UAE were enrolled in this study, which includes 198 males and 232 females. 69\% of the participants were Arabs, $48.1 \%$ were married, and $53.7 \%$ of the participants had a bachelor graduate study.

$13 \%$ of the participants stated that they are suffering from depression or schizophrenia. $10 \%$ of the study sample with the family history of mental diseases. $15 \%$ of the participant attended a health campaign about depression or schizophrenia.

Knowledge data of the respondents about the cause of schizophrenia and depression

Knowledge scores ranged from the lowest score of zero $(0.5 \%)$ to the highest score of 9 (3.5\%) (Fig.1). Mean (standard deviation [SD]) of the knowledge score was 5.84 (1.73).

$80 \%$ (343) had a good knowledge score while 20.2\% (87) had poor knowledge score (Fig. 2). Only two respondents had the lowest score zero, while the highest score achieved among all participants was $7(24.4 \%)$

Table 1: Socialdemographic data. The sociodemographic characteristics of the enrolled UAE population

\begin{tabular}{llll}
\hline Q.No. & Variables & Sub-variables & Frequency (\%) \\
\hline 1 & Gender & Male & $198(46.0)$ \\
& & Female & $232(54.0)$ \\
2 & Nationality & Local & $41(9.5)$ \\
& & Southeastern & $35(8.1)$ \\
& & Arab & $295(68.6)$ \\
3 & \multirow{2}{*}{ Marital status } & Single & $193(44.9)$ \\
& & Married & $207(48.1)$ \\
& & Divorced & $26(6.05)$ \\
4 & \multirow{2}{*}{ Education } & Widow & $4(0.9)$ \\
& & Below HS & $31(7.2)$ \\
& & HS or diploma & $119(27.7)$ \\
& & Bachelor & $231(53.7)$ \\
5 & Attend workshop & Master & $35(8.1)$ \\
& & PhD & $14(3.3)$ \\
6 & Do you have depression & $63(14.7)$ \\
& or schizophrenia & Yo & $367(85.3)$ \\
7 & & & $56(13.0)$ \\
7 & Family history & No & $374(87.0)$ \\
& & Yes & $44(10.2)$ \\
& & No & $386(89.8)$ \\
\hline
\end{tabular}

HS: High school

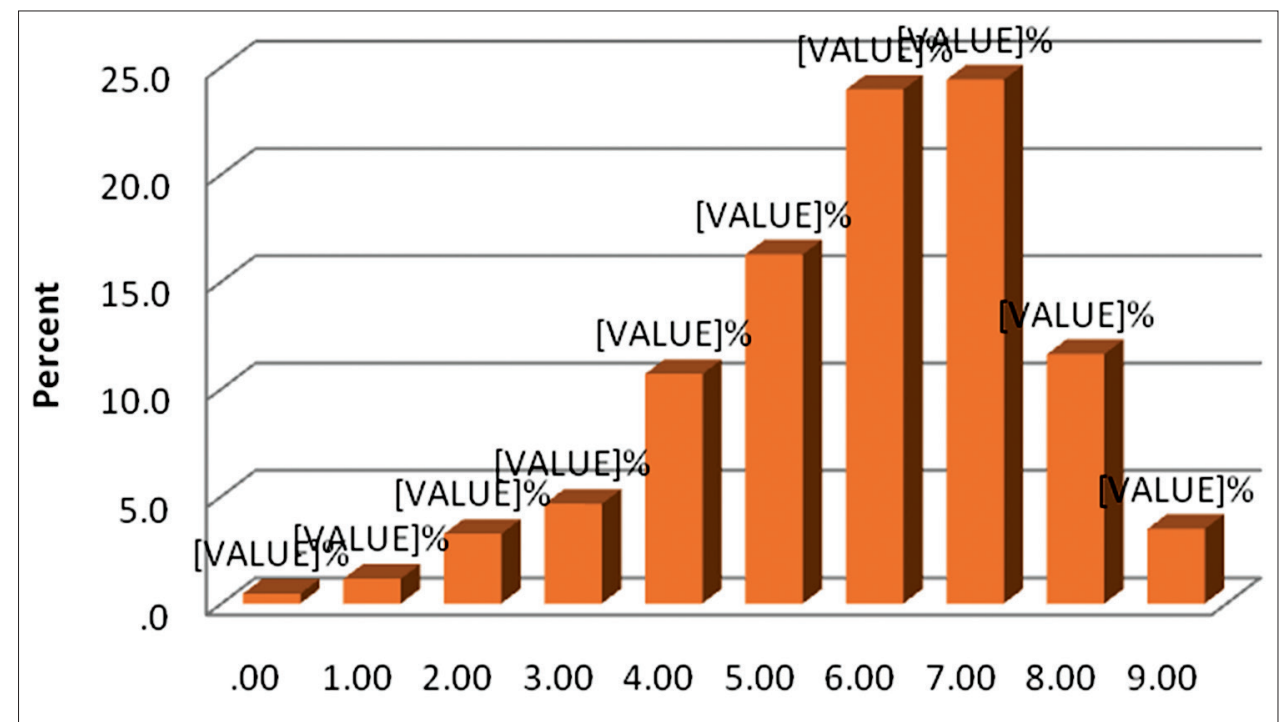

Fig. 1: Distribution of knowledge score. Distribution of participants' knowledge score about the causes of schizophrenia and depression 
$78 \%$ considered that chemical imbalances in the brain are one of the possible causes of mental disorder. $45 \% \mathrm{t}$ disagreed with the fact that genetic is one of the main factors of mental problems. 58\% agreed that magic on someone could result in mental disorder. The details of the responses of the public for knowledge questions are listed in Table 2.

Attitude data of the respondents about schizophrenia and depression

Attitude scores ranged from the lowest score of zero (6\%) to the highest score of 7 (4.2\%) shown in Fig. 3. Mean (SD) of the attitude score is 3.0651 (1.897).

$62 \%$ (266) had negative attitude score while $38.1 \%$ (164) had positive attitude score (Fig. 4). 26 respondents had the lowest score zero, while the highest score achieved among all participants was 2 (19.5\%). $33 \%$ of the participants believe that people with schizophrenia and depression are not dangerous. Only (34.9\%) were not afraid of being close to individuals with depression and schizophrenia while the vast majority stated that they are unpredictable and can result in harm. The details of the responses of the UAE population for attitude questions are listed in Table 3.

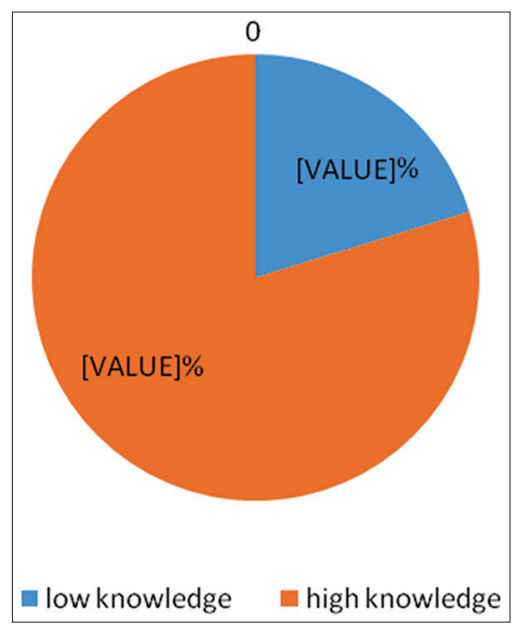

Fig. 2: Respondents knowledge score about schizophrenia and depression. Percentage of participants' knowledge about the causes of schizophrenia and depression

Table 2: Knowledge of mental disorders causes. Participants correct response to knowledge of mental disorders causes

\begin{tabular}{|c|c|}
\hline Questions & $\begin{array}{l}\text { Percent of the } \\
\text { correct answer }\end{array}$ \\
\hline $\begin{array}{l}\text { 1. Genetic is one of the main factors of } \\
\text { contributing the mental disorder }\end{array}$ & 54.7 \\
\hline $\begin{array}{l}\text { 2. A chemical imbalance in the brain is one } \\
\text { of the possible causes of mental disorder }\end{array}$ & 78.4 \\
\hline $\begin{array}{l}\text { 3. Lack of social support contributes a lot to } \\
\text { the occurrence in mental disorder }\end{array}$ & 74.4 \\
\hline $\begin{array}{l}\text { 4. Martial/relationship problem is one of the } \\
\text { main causes that result in mental disorder }\end{array}$ & 62.1 \\
\hline $\begin{array}{l}\text { 5. Frequent alcohol/drug abuse lead to a } \\
\text { mental disorder such as depression and } \\
\text { schizophrenia }\end{array}$ & 82.6 \\
\hline $\begin{array}{l}\text { 6. Childhood trauma or bad memories of the } \\
\text { past can lead to a mental disorders }\end{array}$ & 81.9 \\
\hline $\begin{array}{l}\text { 7. Mental disorders are due to supernatural } \\
\text { and spiritual reasons }\end{array}$ & 40.2 \\
\hline $\begin{array}{l}\text { 8. Casting black magic on someone can } \\
\text { result in mental disorder }\end{array}$ & 58.4 \\
\hline $\begin{array}{l}\text { 9. Financial problems have a major } \\
\text { contribution to resulting mental disorder }\end{array}$ & 49.5 \\
\hline
\end{tabular}

\section{Association between knowledge and attitude}

The relationship between knowledge and attitude toward schizophrenia and depression was investigated using Pearson productmoment correlation coefficient (r). Preliminary analysis was performed to ensure no violation of the assumptions of normality, linearity, and homoscedasticity. There was a positive correlation between the two variables, $r=0.199, p<0.001$. The coefficient of the determination $(R 2)=0.039$. This means that $3.9 \%$ of the variation in attitude was accounted for by the knowledge.

\section{Factors affecting attitude score}

An independent-samples t-test was conducted to compare all of the followings: The attitude score among the categories of gender, salary income, attending workshop, and family history. There was a significant difference in the scores among the having a family history $(\mathrm{p}=0.001)$.

ANOVA test was performed to compare all of the followings: The attitude score among the categories of education, marital status, and nationality. There was a significant difference in the scores and education $(\mathrm{p}=0.017)$ (Table 4$)$.

\section{Factors affecting knowledge score}

An independent-samples t-test was conducted to compare all of the followings: The knowledge score among the categories of gender, salary income, attending workshop, and family history. There was no significant difference among the previous variables (Table 4).

ANOVA test was conducted to compare all of the followings: The knowledge score among the categories of education, marital status, and nationality. There was no significant difference in scores among the previous variables (Table 4).

\section{DISCUSSION}

Stigmatization of mental illnesses is a major burden world wild. Negative public beliefs and attitude toward mental problems become one of the obstacles to community engagement and a barrier for seeking treatment of continuation of therapy.

The current study has revealed a negative attitude (61.9\%) toward people with depression and schizophrenia. These findings are consistent with the findings reported by other studies $[1,23,24]$. The results presented here suggest the urgent need for effective anti-stigma campaign to correct the negative attitudes and promote a positive image of mental illness people. Implementing immediate national health agenda plan with more focus on mental health especially depression and schizophrenia is strongly recommended.

Around one-third of respondents (34.9\%) were not afraid of being close to individuals with depression and schizophrenia while the majority stated that they are unpredictable and can result in harm. These findings reflect a high level of social distance toward people with schizophrenia and depression. This is similar to other studies results $[1,24,25]$. This will have a bearing on patient's reintegration into the community.

There was a widespread belief that people with schizophrenia and depression are dangerous (67.2\%) and not friendly (55.8\%). This is keepingwith previousstudiesfoundabelief thatpeoplewithschizophrenia and depression more aggressive than other people $[1,15,25]$. The public has a high level of concerns about a patient with schizophrenia and depression can be treating their safety. Thus, addressing dangerousness between person with schizophrenia or depression and a healthy person should be the objective priority for future anti-stigma campaign.

The study data show that UAE population is highly knowledgeable about the causes of schizophrenia and depression (79.8\%). Similar to this, the previous surveys reported more knowledge about mental illness $[20,23]$. Although of being highly knowledgeable about the causes of schizophrenia and depression, the majority of the participants had a negative attitude. Future research should be aiming to explore 


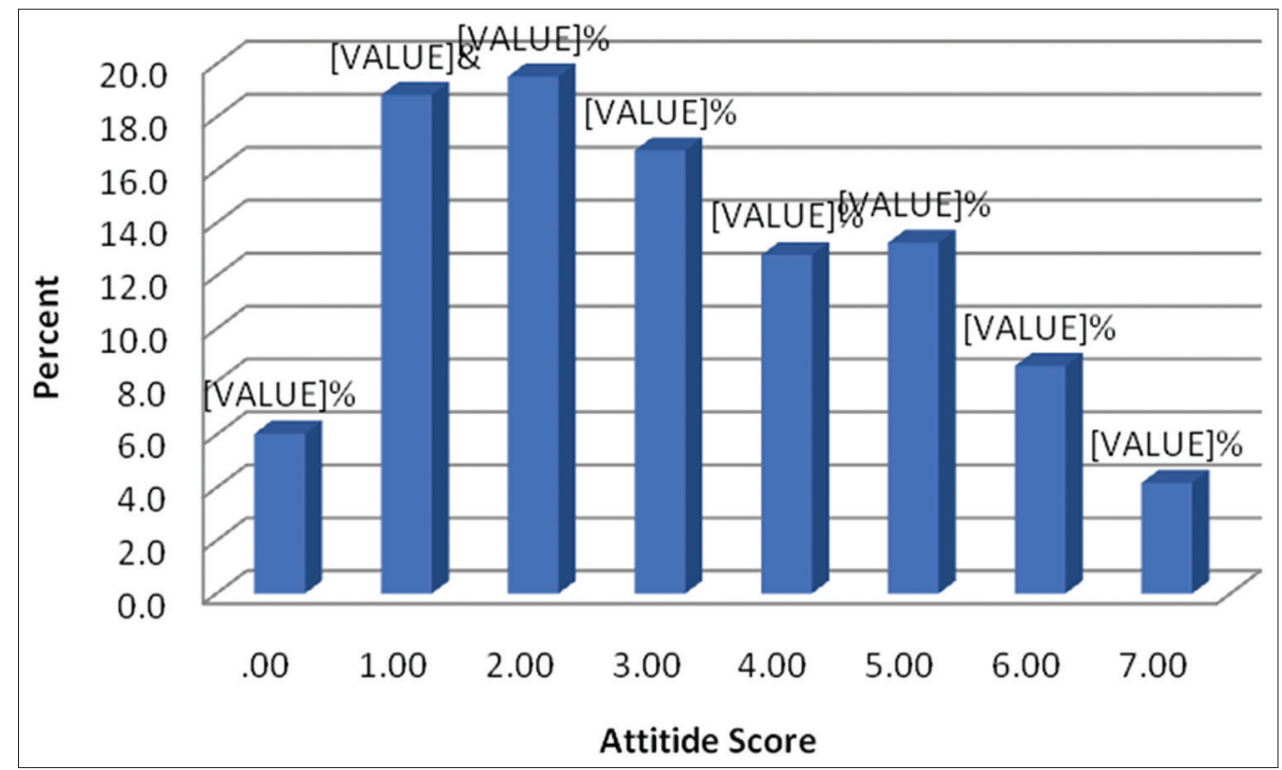

Fig. 3: Distribution of attitude score. Distribution of participants' attitude score about schizophrenia and depression

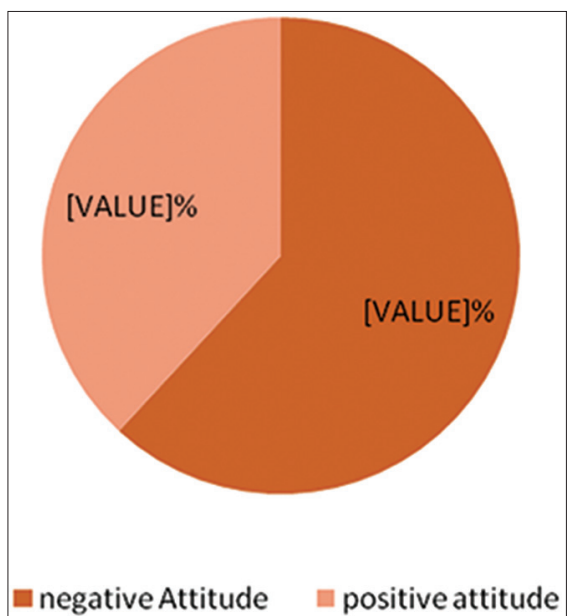

Fig. 4: Respondents attitude. Percentage of participants' attitude about schizophrenia and depression

and discover the factors affecting the attitude and beliefs of UAE public regarding mentally ill patients.

The most frequently recognized causes for schizophrenia and depression were frequent alcohol/drug abuse (82.6\%), followed by childhood trauma or bad memories of the past (81.9\%), and chemical imbalance in the brain $(78.4 \%)$. Our finding parallel with another study reported that $60-70 \%$ of participants agreed with the statement that genetic and chemical imbalance could be a leading cause of mental diseases [1]. On the other hand, other findings showed that environmental causes and stress are the major cause of mental illnesses.

The majority of the participants agreed marital, and relationship problems are one of the main cause of mental disorders (62.1\%). These findings comply with other studies findings [1]. Surprisingly, the results show $41.6 \%$ believe that magic on someone can result in mental disorder. Similarly, studies addressed supernatural beliefs as mental illness cause [1]. In the absence of real-world experience with depression and schizophrenia, public highly influenced with media information [16]. Media plays an important role in such public beliefs, as numerous media films represent the association between magic and psychological, mental health status [1].
One of the important findings revealed in the study was the positive correlation between knowledge and attitudes toward depression and schizophrenia, $r=0.199, p<0.001$. The coefficient of the determination $(\mathrm{R} 2)=0.039$. This means that $3.9 \%$ of the variation in attitude was accounted for by the knowledge. Thus, if the knowledge improved, then the public attitude will also improve which would be reflected in the respondents' approach toward patients with mental disorders in a positive manner.

The present study discovered that there is a significant difference $(p<0.05)$ in attitude scores for participants with family history of mental diseases and those without a family history. Participants with a family history have more positive attitude (54.5\%) toward the patient with depression and schizophrenia. This finding is consistent with other findings where family members have a much higher level of a positive attitude than general public without any family experiences of mental health problems [15].

\section{CONCLUSION}

The study findings revealed a high level of stigma among UAE population toward people with schizophrenia and depression. The negative attitude emphasizes the importance to increase MHL. Such evidence suggests it is essential to modify the national mental health policy in UAE to include interventions that are more effective. Many strategies can be taken as efforts to maintain the public knowledge and correct their attitude. First, campaigns that fight stigmatization and discrimination of people suffering from mental illness and promote social integration in the community. This campaign should increase the awareness about the recognition, causes, and treatment of schizophrenia and depression. Second, media publicity is a valuable tool to address the misunderstanding and disbeliefs about mental diseases. Another approach that can eliminate the delay in help-seeking and shorten the negative social distance among mentally ill people is to implement mental health agencies. Such agencies can encourage patients and their families to have a partnership with health care providers, educators and treatment centers to develop a society with adequate MHL.

\section{AUTHOR'S CONTRIBUTION}

All authors developed the protocol of the study. Sundos Qassim and Yassin Al-Hariri analyzed and interpreted the data. Sundos Qassim wrote the initial draft. Yassin Al-Hariri and Fatima Boura edited the manuscript. All authors contributed to the final draft. 
Table 3: Attitude toward patients. Participants' positive attitude response to people with depression and schizophrenia

\begin{tabular}{ll}
\hline Questions & $\begin{array}{l}\text { Percent of } \\
\text { positive attitude }\end{array}$ \\
\hline $\begin{array}{l}\text { 1. Individuals with mental disorders are crazy } \\
\text { 2. They are dangerous }\end{array}$ & 59.5 \\
$\begin{array}{l}\text { 3. Individuals with mental disorders are not } \\
\text { friendly }\end{array}$ & 32.8 \\
$\begin{array}{l}\text { 4. I am afraid of being close to such } \\
\text { individuals, they are unpredictable and can } \\
\text { result in harm }\end{array}$ & 34.9 \\
$\begin{array}{l}\text { 5. Individuals with mental disorder patients } \\
\text { are moody }\end{array}$ & 13.3 \\
$\begin{array}{l}\text { 6. What do you think; individuals with mental } \\
\text { disorders are kind }\end{array}$ & 32.3 \\
$\begin{array}{l}\text { 7. They have disturbing/negative thoughts; } \\
\text { therefore, it's better to avoid them }\end{array}$ & 45.6 \\
\hline
\end{tabular}

Table 4: Factors affecting participants' knowledge and perception score. The $p$ value of the participants' knowledge and perception scores among sociodemographic variables

\begin{tabular}{lll}
\hline Variables & $\begin{array}{l}\text { Perception score } \\
\text { p value }\end{array}$ & $\begin{array}{l}\text { Knowledge score } \\
\text { p value }\end{array}$ \\
\hline Nationality & $0.20^{\mathrm{A}}$ & $0.470^{\mathrm{A}}$ \\
Marital status & $0.339^{\mathrm{A}}$ & $0.426^{\mathrm{A}}$ \\
Education & $0.017^{* \mathrm{~A}}$ & $0.285^{\mathrm{A}}$ \\
Gender & $0.450^{\mathrm{T}}$ & $0.705^{\mathrm{T}}$ \\
Monthly income & $0.230^{\mathrm{T}}$ & $0.341^{\mathrm{T}}$ \\
Attended workshop & $0.434^{\mathrm{T}}$ & $0.503^{\mathrm{T}}$ \\
Family history & $0.001^{* \mathrm{~T}}$ & $0.604^{\mathrm{T}}$ \\
\hline
\end{tabular}

${ }^{\mathrm{A}}$ ANOVA test, ${ }^{\mathrm{T}}$ Independent T-test, ${ }^{*} \mathrm{p}<0.05$

\section{CONFLICTS OF INTEREST}

There were no conflicts of interest in this study.

\section{REFERENCES}

1. Khan TM, Hassali MA, Tahir H, Khan A. A pilot study evaluating the stigma and public perception about the causes of depression and schizophrenia. Iran J Public Health 2011;40:50-6.

2. Wu Q, Luo X, Chen S, Qi C, Long J, Xiong Y, et al. Mental health literacy survey of non-mental health professionals in six general hospitals in Hunan Province of China. PloS One 2017;12:180327-40.

3. Mishra S, Swain T, Mohanty T. Patterns of prescription and efficacy evaluation of antidepressants in a tertiary care teaching hospital in eastern India. Asian J Pharm Clin Res 2012;5:193-6.

4. Roopadevi HS, Ramesh KS, Nagabushan H. Pattern of psychotropic prescription in a tertiary care teaching hospital: A critical analysis. Asian J Pharm Clin Res 2015;8:252-5.

5. Swami V, Furnham A, Kannan K, Sinniah D. Beliefs about schizophrenia and its treatment in Kota Kinabalu, Malaysia. Int J Soc Psychiatry 2008;54:164-79.

6. Kurumatani T, Ukawa K, Kawaguchi Y, Miyata S, Suzuki M, Ide $\mathrm{H}$, et al. Teachers' knowledge, beliefs and attitudes concerning schizophrenia. Soc Psychiatry Psychiatr Epidemiol 2004;39:402-9.

7. Jorm AF, Korten AE, Jacomb PA, Christensen H, Rodgers B, Pollitt P. Mental health literacy. a survey of the public's ability to recognise mental disorders and their beliefs about the effectiveness of treatment. Med J Aust 1997;166:182-6.

8. Mohamad MS, Zabidah P, Fauziah I, Sarnon N. Mental health literacy among family caregivers of schizophrenia patients. Asian Soc Sci 2012;8:74-82

9. DeWalt DA, Berkman ND, Sheridan S, Lohr KN, Pignone MP. Literacy and health outcomes. J Gen Intern Med 2004;19:1228-39.

10. Lauber C, Nordt C, Falcato L, Rössler W. Do people recognise mental illness. Eur Arch Psychiatry Clin Neurosci 2003;253:248251.

11. Furnham A. Psychiatric and psychotherapeutic literacy: Attitudes to, and knowledge of, psychotherapy. Int $\mathrm{J}$ Soc Psychiatry 2009;55:525-37.

12. Mubarak AR. Malaysia's social policies on mental health: A critical theory. J Health Soc Pol 2003;17:55-72.

13. Link BG, Phelan JC. Conceptualizing stigma. Annu Rev Sociol 2001;27:363-85.

14. Dietrich S, Beck M, Bujantugs B, Kenzine D, Matschinger H, Angermeyer MC. The relationship between public causal beliefs and social distance toward mentally ill people. Aust N Z J Psychiatry 2004;8:348-54.

15. Thompson AH, Stuart H, Bland RC, Arboleda-Florez J, Warner R, Dickson RA. Attitudes about schizophrenia from the pilot site of the WPA worldwide campaign against the stigma of schizophrenia. Soc Psychiatry Psychiatr Epidemiol 2002;37:475-82.

16. Alexander L, Link B. The impact of contact on stigmatizing attitudes toward people with mental illness. J Ment Health 2003;12:271-89.

17. Lauber C, Nordt C, Falcato L, Rössler W. Factors influencing social distance toward people with mental illness. Community Ment Health J 2004:40:265-74.

18. Gaebel W, Baumann AE. Interventions to reduce the stigma associated with severe mental illness: Experiences from the open the doors program in Germany. Can J Psychiatry 2003;48:657-62.

19. Highet NJ, Hickie IB, Davenport TA. Monitoring awareness of and attitudes to depression in Australia. Med J Aust 2002;176:S63-8

20. Stuart H, Florez JA. Community attitudes toward people with schizophrenia. Can J Psychiatry 2001;46:245-52.

21. Magliano L, Fiorillo A, De Rosa C, Malangone C, Maj M. Beliefs about schizophrenia in Italy: A comparative nationwide survey of the general public, mental health professionals, and patients' relatives. Can J Psychiatry 2004:49:323-31.

22. Raosoft. An Online Sample Size Calculator; 2008. Available from: http://www.raosoft.com/samplesize.html.[Last cited on 2018 Feb 20].

23. Javed Z, Naeem F, Kingdon D, Irfan M, Izhar N, Ayub M. Attitude of the university students and teachers towards mentally ill, in Lahore, Pakistan. J Ayub Med Coll Abbottabad 2006;18:55-63.

24. Nordt C, Rössler W, Lauber C. Attitudes of mental health professionals toward people with schizophrenia and major depression. Schizophr Bull 2006;32:709-14.

25. Wolff G, Pathare S, Craig T, Leff J. Community knowledge of mental illness and reaction to mentally ill people. T Br J Psychiatry 1996;168:191-8. 